\title{
Experimental Investigation of Drilling Fluid Performance as Nanoparticles
}

\author{
Jamal Nasser $^{1}$, Anna Jesil ${ }^{1 *}$, Tariq Mohiuddin ${ }^{2}$, Majid Al Ruqeshi ${ }^{2}$, \\ Geetha Devi ${ }^{1}$, Shahjahan Mohataram ${ }^{1}$ \\ ${ }^{1}$ Mechanical \& Industrial Engineering Department, Caledonian College of Engineering, Muscat, Oman \\ ${ }^{2}$ Sultan Qaboos University, Al khoudh, Oman \\ Email: *annajesil@gmail.com
}

Received June 25, 2013; revised July 25, 2013; accepted August 2, 2013

Copyright (c) 2013 Jamal Nasser et al. This is an open access article distributed under the Creative Commons Attribution License, which permits unrestricted use, distribution, and reproduction in any medium, provided the original work is properly cited.

\begin{abstract}
In this work, a drilling fluid recipe has been developed by using nanoparticles, to increase the efficiency of drilling operations for maximum accessibility to new \& matured oil reserves and suited to various drilling conditions. The solution to severe drilling problems like pipe sticking, lost circulation, formation damage, erosion of borehole, thermal instability of drilling fluids and insufficient gel properties of the drilling fluids, lies in controlling and optimizing the rheology of the drilling fluid. The inefficiency of the drilling fluid in performing certain functions is mainly due to a lack in a particular rheological property. The performance of the clay composites water-based bentonite drilling mud in terms of its rheological behavior in drilling systems was investigated at various pressures and temperatures. It was found that temperature had a detrimental effect on the rheological properties. The behavior was investigated using synthesized nano bentonite water based drilling fluid. The fluid retained all the desired rheological properties at elevated temperatures and pressures, thus enhanced the possibility of its application in deep wells, where elevated temperatures and pressures were quite common.
\end{abstract}

Keywords: Drilling Fluid; Nanoparticles; Mud; Viscosity; Density

\section{Introduction}

Drilling deeper, longer and more challenging wells has been made possible by improvements in drilling technologies, including more efficient and effective drilling fluids. Drilling fluids, also referred to as drilling mud, are added to the wellbore to facilitate the drilling process by suspending cuttings, controlling pressure, stabilizing exposed rock, providing buoyancy, and cooling and lubricating.

As early as the third century BC, the Chinese were using drilling fluids, in the form of water, to help permeate the ground when drilling for hydrocarbons. The term "mud" was coined when at Spindle top in the US. Drillers ran a herd of cattle through a watered-down field and used the resulting mud to lubricate the drill.

While the technology and chemistry of drilling fluids have become much more complex, the concept has remained the same. Drilling fluids are essential to drilling success, both maximizing recovery and minimizing the amount of time it takes to achieve first oil.

\footnotetext{
${ }^{*}$ Corresponding author.
}

The cost of the fluid system often represents one of the single greatest capital outlays in drilling an oil well. To minimize the cost of fluids and to ensure an efficient drilling program, the fluid properties must be maintained continuously during the drilling operation. In addition, the high temperature $\&$ high pressure conditions faced in ultra-deep oil \& gas drilling environments pose major challenges for the fluids used in drilling operations. The degradation of drilling fluids in these environments reduces drilling efficiency by slowing the rates of penetration \& creates severe problems that leads to leaving behind most of the oil unrecovered.

The rotational viscometer has been designed which permits the measurement of the rheological properties of drilling muds and other non-Newtonian fluids under conditions equivalent to those in a deep borehole $\left(350^{\circ} \mathrm{F}\right.$, $10,000 \mathrm{psi})$. The important mechanical features of this instrument are described, and its design criteria are discussed [1]. The flow equations for the novel configuration of the viscometer are derived and the calibration procedures are described. The date and their interpretation, resulting from measurement of the flow properties 
and static gel strengths of homoionic montmorillonite suspensions at high temperatures and pressures, are presented. Data are also presented for the flow behavior of typical drilling fluids at high temperatures and pressures. The pressure losses in the drill pipe and the annulus depend critically upon the flow parameters of the drilling fluid. Their work demonstrates the need to measure these parameters under bottom-hole conditions in order to obtain a reliable estimate of the pressure losses in the mud system. Nanoparticles, a unique subset of the broad field of nanotechnology, include any type of particle with at least one dimension of less than 500 nanometers [2]. Nanoparticles play an important role in a wide variety of fields including advanced materials, pharmaceuticals, and environmental detection and monitoring.

The atomic force microscope (AFM) is ideally suited for characterizing nanoparticles. It offers the capability of $3 \mathrm{D}$ visualization and both qualitative and quantitative information on many physical properties including size, morphology, surface texture and roughness. Statistical information, including size, surface area, and volume distributions, can be determined as well. A wide range of particle sizes can be characterized in the same scan, from 1 nanometer to 8 micrometers. In addition, the AFM can characterize nanoparticles in multiple mediums including ambient air, controlled environments, and even liquid dispersions.

Bentonite is employed by industry to perform a multitude of jobs [3]. Certain industrial applications become apparent from an understanding of the composition and structure of bentonite, and the properties they create. These properties are utilized chiefly when the material is suspended in a liquid, usually water; or as a dried powder or granule. Most industrial applications involve the swelling property of bentonite to form viscous water suspensions. Depending upon the relative proportions of clay and water, these mixtures are used as bonding, plasticizing, and suspending agents. Bentonites disperse into colloidal particles and, accordingly, provide large surface areas per unit weight of clay. This large surface area is a major reason why bentonite functions so well in stabilizing emulsions, or as a medium to carry other chemicals. Bentonites react chemically with many organic materials to form compounds which are used chiefly as gelling agents in a variety of organic liquids. Bentonites are selected for each industrial need on the basis of type and quality. This selection is based principally on physical properties, and chemistry of the bentonite becomes involved only to the extent that it influences the physical properties.

Drilling fluids are used in drilling operations to cool and lubricate the drill bit, remove rock debris and drill cuttings from the site and to counteract down hole formation pressures. Research is being conducted to develop nanoparticle-amended drilling fluids with en- hanced functionalities. Such enhancements include improved rheological, thermal, mechanical, magnetic and optical profiles. These drilling fluids will have close to real time responsiveness (for example viscosity) to changing conditions down hole. Researchers at the National Energy Technology laboratory are designing an environmentally-friendly nanofluid for oil and gas exploration and drilling that can withstand the high temperatures and pressures in deep and horizontal drilling operations. To tackle the challenge of controlling the rheological profile of drilling muds in situ in response to changing environmental conditions down hole, super paramagnetic iron oxide nanoparticles are being added to create drilling fluids with viscosities that can be rapidly altered in situ by applying a magnetic field. Similarly, the addition of carbon nanoparticles is effective at controlling the viscosity of drilling muds. The addition of nanoparticles to drilling muds can also be used to remove the highly toxic and corrosive Hydrogen sulphide gas that diffuses into drilling fluids during drilling operations.

Researchers [4] have found that the addition of nanoscale Zinc oxide to drilling muds removes $100 \%$ of hydrogen sulphide from water-based drilling muds within 15 minutes, whereas bulk Zinc oxide removes only $2.5 \%$ after 90 minutes of treatment.

Enhanced retention or solubilization of a contaminant may be helpful in a remediation setting. Nanomaterials may be useful in decreasing sequestration of hydrophobic contaminants, such as Polycyclic aromatic hydrocarbons (PAHs), bound to soils and sediments [4]. The release of these contaminants from sediments and soils could make them more accessible to in situ biodegradation. For example, nanomaterials made from Poly(ethylene) Glycol modified Urethane Acrylate have been used to enhance the bioavailability of Phenanthrene.

Metal remediation has also been proposed, using zerovalent iron and other classes of nanomaterial. Nanoparticles such as polyamidoamine dendrimers can serve as chelating agents, and can be further enhanced for ultrafiltration of a variety of metal ions (Cu(II), $\mathrm{Ag}(\mathrm{I})$, $\mathrm{Fe}(\mathrm{III})$, etc.) by attaching functional groups such as primary Amines, carboxylates, and hydroxymates [5]. Other research indicates that arsenite and arsenate may be precipitated in the subsurface using zero-valent iron, making arsenic less mobile [5]. Self-assembled monolayers on mesoporous supports (SAMMS) are nanoporous ceramic materials that have been developed to remove Mercury or radionuclides from wastewater [5].

Nanomaterials have also been studied $[8,9]$ for their ability to remove metal contaminants from air. Silicatitania nanocomposites can be used for elemental mercury removal from vapors such as those coming from combustion sources, with silica serving to enhance adsorption and Titania to photocatalytically oxidize elemental mercury to the less volatile mercuric oxide [7]. 
Other authors have demonstrated nanostructured silica can adsorb other metals generated in combustion environments, such as lead and cadmium [8,9]. Certain nanostructured sorbent processes can be used to prevent emission of nanoparticles and create byproducts that are useful nanomaterials.

There are additional emerging innovative approaches [6] to energy management that could potentially reduce energy consumption. For example, nanomaterials arranged in superlattices could allow the generation of electricity from waste heat in consumer appliances, automobiles, and industrial processes. These thermoelectric materials could, for example, further extend the efficiencies of hybrid cars and power generation technologies.

\section{Experimental}

\subsection{Synthesis of Nanoparticles and Normal Drilling Mud}

There are several methods for creating nanoparticles, including both attrition and pyrolysis. The synthesis and application of nanoparticles is one of the most interesting filed of research from basic and applied point of views. The use of water-in-oil micro emulsions for the synthesis of nanoparticles is one of the most promising methods. For this work, nanoparticles for use as nanomud was prepared by mixing Nanographite and Nanosilicon wires. The composition of the nanomud was Bentonite (69\%), Barite(19\%), Starch (9\%) and nano (3\%).The normal mud was prepared by mixing Bentonite, Barite and starch in the proportions $70 \%, 20 \%$ and $10 \%$ by weight.

\subsection{Characterisation of the Nanoparticles}

The specification of the Nanographite used is given below:

- Graphite (synthetic) powder

- Purity: 99.9\%

- APS (Particle size): $40 \mathrm{~nm}$

- SSA( surface area/mass): $>60 \mathrm{~m}^{2} / \mathrm{g}$

- Morphology: spherical

- Bulk density: $\sim 0.26 \mathrm{~g} / \mathrm{cm}^{3}$

- True density: $2.26 \mathrm{~g} / \mathrm{cm}^{3}$

Figures 1 and 2 show transmission electron microscopy imaging (Hitachi) and the $\mathrm{x}$ ray diffraction pattern of the nanographite.

Figure 3 shows the surface morphology of the Silicon nanowires used. The morphology showed long solid wires with a high surface area to volume ratio.

\subsection{Determination of Mud Density}

The Baroid Mud Balance as shown below in (Figure 4) is used to determine density of the drilling fluid. The instrument consists of a constant volume cup with a lever arm and rider calibrated to read directly the density of the fluid.

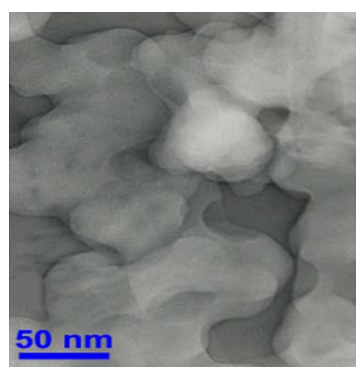

Figure 1. TEM imaging of nanographite.

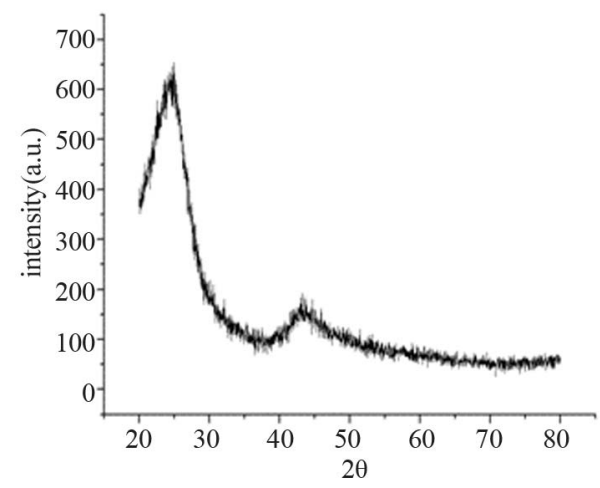

Figure 2. X ray diffraction pattern of the nanographite.

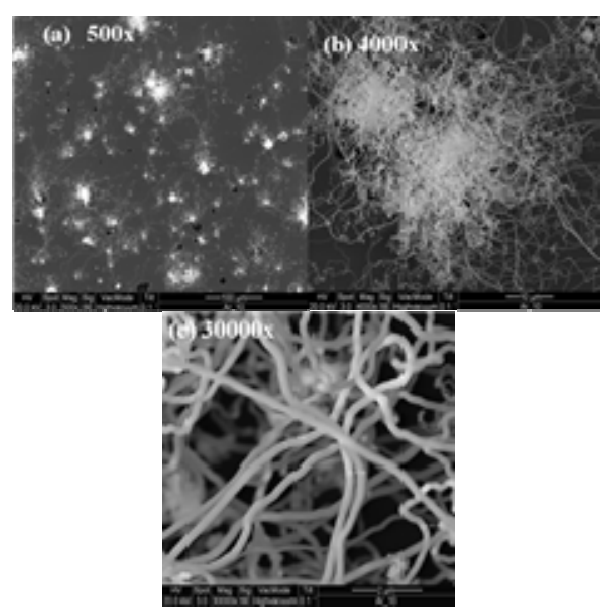

Figure 3. Scanning electron microscope (SEM) images of Silicon nanowires under $1200^{\circ} \mathrm{C}$.

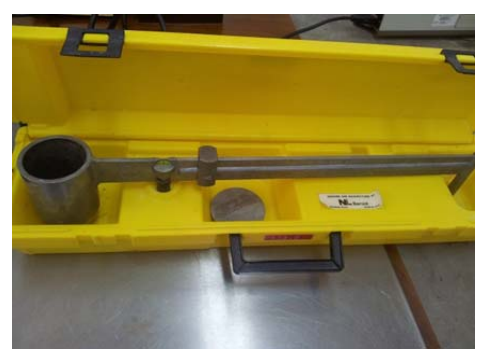

Figure 4. Mud balance. 
Before testing densities of drilling fluid samples, mud balance must first be calibrated by using water as the sample. The density of water is $1 \mathrm{gm} / \mathrm{cc}$. After measureing density of mud sample and mud synthesized from nanoparticles, the true density is calculated.

\subsection{Determination of Viscosity}

The viscosity of a fluid is defined Rheology refers to the deformation and flow behavior of all forms of matter. Certain rheologic measurements made on fluids, such as viscosity, gel strength, etc. help determine how this fluid will flow under a variety of different conditions. This information is important in the design of circulating systems required to accomplish certain desired objectives in drilling operations as its resistance to flow. The desired viscosity for a particular drilling operation is influenced by several factors, including mud density, hole size, pumping rate, drilling rate, pressure system and requirements, and hold problems. The indicated viscosity as obtained by instrument (Figure 5) is valid only for that rate of shear and will differ to some degree when measured at a different rate of shear.

\subsection{Measurement of Mud Filtrate Loss}

Fluid loss is the measurement of filtrate passing from the drilling fluid into a porous permeable formation. Low fluid loss is a characteristic of good drilling fluids and the key to borehole integrity. The goal of a good drilling fluid is to create a thin filter cake on the sides of the borehole. This prevents the excessive loss of fluids into the formation.

The drill pipe may stick to the wall of the hole due to the formation of filter cake or a layer of wet mud solids on the wall of the hole in the formation. The filtrate loss at different pressures is measured using the instrument shown in Figure 6.

The mud cake which is the compacted solid or semisolid material remaining on a filter after pressure filtration of mud with standard filter press is shown in Figure 7.

\subsection{Friction Measurement}

Fluid friction describes the friction between layers within
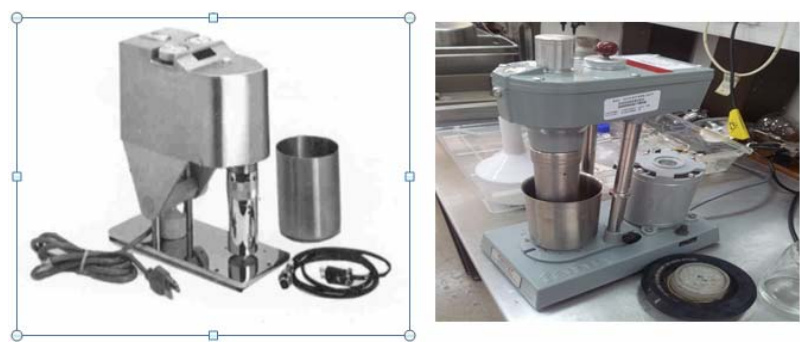

Figure 5. Viscosity measuring instrument. a viscous fluid that are moving relative to each other.

When surfaces in contact move relative to each other, the friction between the two surfaces converts kinetic energy into heat. This property can have dramatic consequences, as illustrated by the use of friction created by rubbing pieces of wood together to start a fire. Kinetic energy is converted to heat whenever motion with friction occurs, for example when a viscous fluid is stirred. Another important consequence of many types of friction can be wear, which may lead to performance degradation and/or damage to components. The instrument for measuring the friction of the nanomud is shown in Figure 8. The friction is measured in terms of the inclination angle that is related to the roughness.

\section{Results and Discussion}

\subsection{Density Measurement}

Using water as the reference, the density of the nano mud was found to be $2.2 \mathrm{~g} / \mathrm{cm}^{3}$, while that of the normal fluid mud was found to be $1.4 \mathrm{~g} / \mathrm{cm}^{3}$.

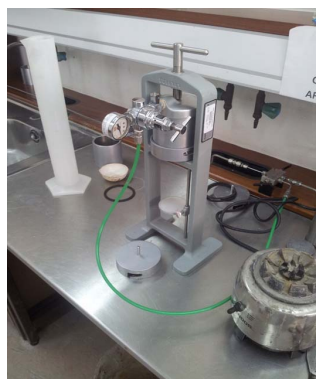

Figure 6. Measurement of mud fluid loss.

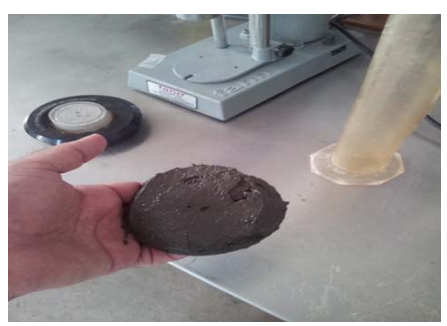

Figure 7. Mud cake.

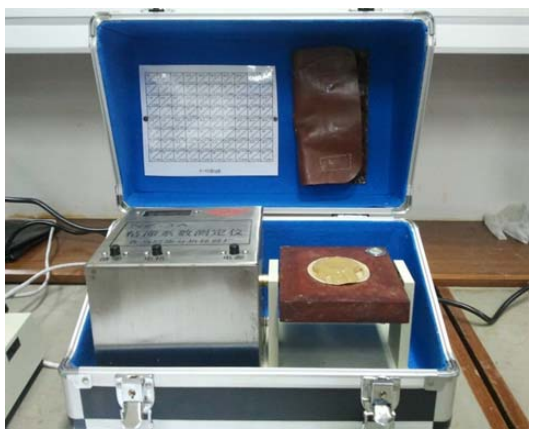

Figure 8. Measurement of viscosity. 


\subsection{Mud Viscosity}

The graph below (Figure 9) shows the effect of temperature and speed on the viscosity. The viscosity of the nanomud is higher than the normal drilling mud at a particular temperature. As the temperature and speed increases, the viscosity of the muds decreases.

\subsection{Mud Filtrate Loss}

The effect of the pressure on the mud measured in terms of the fluid loss has been shown in Figure 10. It can be inferred that the normal drilling mud will loose its fluidity with increase in pressure. This loss is less for the nanomud.

\subsection{Mud Friction}

Table 1 shows the degree of mud cake roughness between normal mud and mud constituted of nano particles. When the time is increased the roughness of the mud will

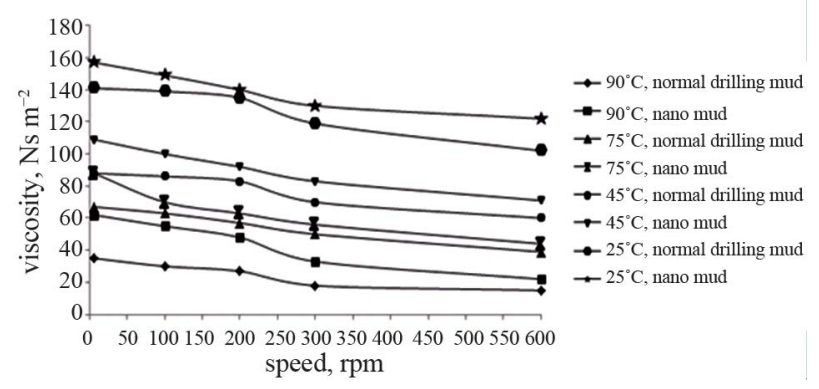

Figure 9. Effect of temperature and speed

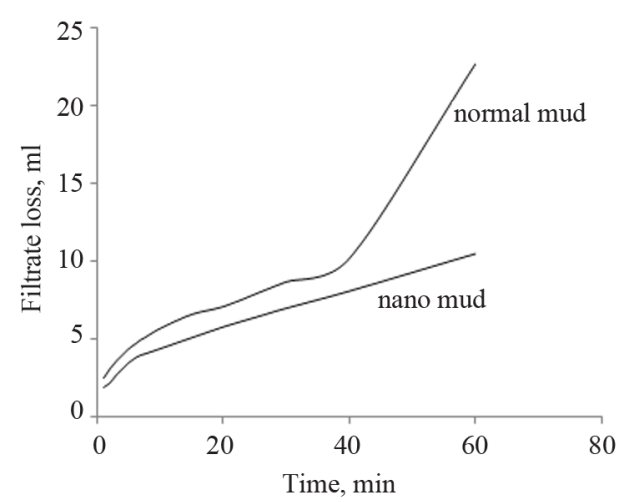

Figure 10. Fluid loss for the nanomud and normal mud with increase in pressure

Table 1. Measure of friction for mud cake of normal mud and nano mud.

\begin{tabular}{ccc} 
Time & Normal mud & Nano mud \\
$40 \mathrm{~min}$ & $8^{\circ}$ & $3^{\circ}$ \\
$60 \mathrm{~min}$ & $12^{\circ}$ & $7^{\circ}$ \\
\hline
\end{tabular}

increase because of the increase in pressure with time will lead to more fluid loss and thus increase roughness.

By comparing between the normal mud and the nano mud, the normal mud has more roughness than the other mud because, the nano mud is less effected by increase of pressure in terms of fluid loss.

\section{Conclusion}

From this work, it can be inferred that drilling mud modified by adding nanoparticles has better maintenance of the rheological properties at higher pressure and temperature. This experimental work shows that nano technology can be used for enhancing the properties of drilling fluids. Future work can be done in the area of measurement of more properties to make a better comparative study. The cost feasibility can also be worked out as synthesizing nanoparticles which are quite costly.

\section{REFERENCES}

[1] K. H. Hiller, "Rheological Measurements on Clay Suspensions and Drilling Fluids at High Temperatures and Pressures,” Petroleum Technology, Vol. 15, No. 7, 1963, pp. 779-788.

[2] J. Scalf and P. West, "Introduction to Nanoparticle Characterization with AFM,” Pacific Nanotechnology, Vol. 16, 2006, pp. 1-8.

[3] A.G Clenand R. W. Doehler, "Industrial Application of Bentonite," Proceedings of the Tenth National Conference on Clays and Clay Minerals, 1963.

[4] S. C. Remillard, "Applications of Nanotechnology within the Oil and Gas Industry," Oil and Gas Review, Vol. 8, 2010, pp. 1-108.

[5] W. Tungittiplakorn, et al., "Engineered Polymeric Nanoparticles for Bioremediation of Hydrophobic Contaminants,” Environmental Science \& Technology, Vol. 39, No. 5, 2005, pp. 1354-1358. doi:10.1021/es049031a

[6] J. Zhuang and W. Randall, "Environmental Application and Risks of Nanotechnology: A Balanced View,” ACS Symposium Series, Vol. 1079, 2011, pp. 41-67.

[7] E. Pitoniak, et al., "A Desorption Enhancement Mechanisms of Silica-Titania Nanocomposites for Elemental Mercury Vapor Removal,” Environmental Science \& Technology, Vol. 39, No. 5, 2005, pp. 1269-1274.

[8] P. Biswas, "Nanoparticles and the Environment a Critical Review,” Journal of Air \& Waste Management Association, Vol. 55, No. 6, 2005, pp. 708-746.

[9] P. Biswas and Zachariah, "Characterization of Iron Oxide-Silica Nanocomposites in Flames, Part II: Comparison of a Discrete-Sectional Model Predictions to Experimental Data,” Journal of Materials Research, Vol. 12, No. 3, 1997, pp. 714-723. doi:10.1557/JMR.1997.0106 